\title{
A Microcalorimeter for Measuring Self-Discharge of Pacemakers and Pacemaker Power Cells
}

\author{
Edward J. Prosen* and Jennifer C. Colbert* \\ National Bureau of Standards, Washington, D. C. 20234
}

January 23, 1980

\begin{abstract}
The self-discharge heat losses of cardiac pacemaker power cells and pacemakers were investigated by microcalorimetry. Results were obtained with small alkaline, mercury and lithium-iodine batteries under opencircuit and external load conditions to monitor their heat loss characteristics and to gather information on the self-discharge mechanism. Results obtained with "complete pacemakers" are also reported.
\end{abstract}

Key words: Battery; microcalorimeter; pacemaker; power cell; self-discharge.

\section{Introduction}

We have developed a microcalorimeter capable of measuring the small heat losses occurring in pacemaker batteries, small camera and watch batteries and the "complete pacemaker." The small heat loss or self-discharge is a contributing factor in shortening the shelf life of the battery and finally the-useable life of the pacemaker. Under ideal conditions, the pacemaker microcalorimeter is capable of detecting as little as $0.1 \mu \mathrm{W}$. It has been used for obtaining information on the self-discharge mechanism and is being used by the battery and pacemaker industry to develop a non-d estructive test for the complete pacemaker.

Self-discharge can be defined as the gradual loss of deliverable energy when a power cell is stored open-circuit. Hence, self-discharge can limit the time that a power cell will be able to provide power for a pacemaker. The self-discharge mechanism is not completely understood, also the self-discharge rate varies for different power cells and for different manufacturing conditions. Therefore, it would be expected that measurement of the self-discharge heat of batteries manufactured under known conditions could help to obtain a better understanding of its causes.

Microcalorimetry can measure open-circuit self-discharge heat losses and therefore can non-destructively discover batteries with inordinately large self-discharge heats; and, using such data, limits can be set on the time a battery can be stored before usage without undue power loss. Measurements on the complete pacemaker constitute a non-destructive test which can help detect any pacemaker that draws too much power. This would be a useful test that can be performed after the hermetic sealing of the unit.

The measurement of these small heat losses was undertaken first in a feasibility study with small camera and watch batteries which could fit easily into the existing NBS Batch Microcalorimeter [1]. ${ }^{1}$

\section{Design of Batch Microcalorimeter}

The Batch Microcalorimeter, sketched in figure 1 , is a heat-conduction microcalorimeter. An aluminum block or

NBS Microcalorimeter

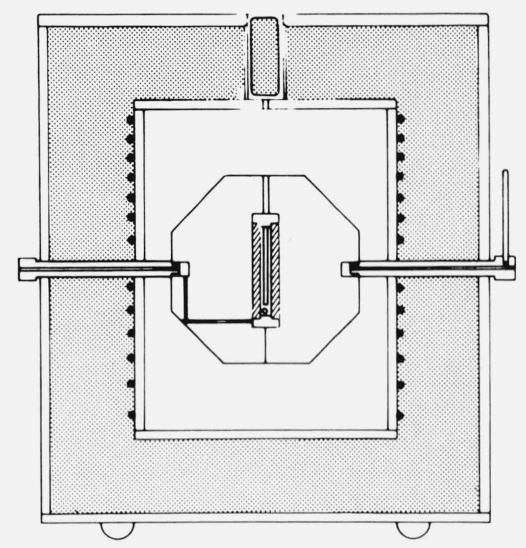

FIGURE 1. Schematic of NBS Conduction Microcalorimeter 
heat sink is centered inside an inner aluminum can which in turn is surrounded by a larger aluminum can. The two aluminum cans protect the heat sink from any sudden changes in room temperature. Polyurethane foam insulates the air space between the inner and outer cans. A heating wire and wires of a Wheatstone bridge were wrapped around the inner can to control its temperature to within \pm $0.001{ }^{\circ} \mathrm{C}$. All measurements are made inside the heat sink which contains a calorimeter compartment or sample box into which microcalorimeter vessels with sample material are placed. The heat flow detector surrounds the outer sample box. The detector consists of multiple-junction thermocouples with its inner face in good contact with the calorimeter and its outer face in good contact with the aluminum block.

The detectors are N-type and P-type solid state thermopiles (Metal Specialties Company) ${ }^{2}$ with an output of $1 \mu \mathrm{V}$ for every $4.90 \mu \mathrm{W}$ of power generated within the sample box. An operational amplifier (Analog Device $261 \mathrm{~K}$ ), kept at a constant temperature $\left( \pm 0.001{ }^{\circ} \mathrm{C}\right)$ within the calorimeter shield, amplifies the output by 1000 . The output voltage is recorded by a millivolt potentiometer recorder or read by a digital voltmeter. The data are recorded on magnetic tape cassettes, and plotted during the experiment.

The noise level and stability of the microcalorimeter are within a few tenths of a microwatt. The calibration factor of $4.90 \mu \mathrm{W} / \mu \mathrm{V}$ was determined by using a four lead electrical heater in the sample box and is the value used to convert signal output in $\mu \mathrm{V}$ to power in $\mu \mathrm{W}$.

The microcalorimetric sample box measured 3.8 by 2.8 by $0.8 \mathrm{~cm}$. Because of its small size, the larger pacemaker power cells could not be used; therefore, small camera and watch power cells were used to test the feasibility of the microcalorimetric method.

\section{Experimental Data on camera and watch batteries}

The batteries used in the feasibility study are described in table 1. To improve the thermal contact between the power cell and sample box, an electrically non-conducting hydrocarbon oil (Cenco Hyvac Oil) was added to the sample box to just cover the power cell. We placed transparent adhesive tape over one battery terminal to prevent shorting to the box and used a string to lower the battery into the oil filled sample box.

Figure 2 shows a recording of the self-discharge of power cell X-5, a mercury watch battery. The initial portion of the plot is the calorimeter baseline without any power cell in the sample box. When the power cell was inserted, the output

\footnotetext{
2 The commercial items or products identified in this paper are included to adequately describe the instrumentation and experimental procedure. Such identification does not imply recommendation or endorsement by the National Bureau of Standards.
}

TABLE 1. Battery Description

\begin{tabular}{|c|c|c|c|}
\hline $\begin{array}{l}\text { Battery } \\
\text { No. }\end{array}$ & Type & Use & $\begin{array}{c}\text { Size }, \mathrm{cm} \\
\text { Diameter } \times \text { Thickness }\end{array}$ \\
\hline $\mathrm{X}-2$ & alkaline & camera ...... & $2.3 \times 0.6$ \\
\hline $\mathrm{X}-3$ & mercury. ..... & camera ...... & $1.55 \times 0.6$ \\
\hline $\mathrm{X}-4$ & alkaline. . & camera ...... & $2.3 \times 0.6$ \\
\hline$X-5$ & mercury. ..... & watch $\ldots \ldots$. & $1.15 \times 0.35$ \\
\hline$X-6$ & mercury. ..... & camera ...... & $1.55 \times 0.6$ \\
\hline
\end{tabular}

increased (the exothermic direction is downward on the plot.) Since the power cell was not initially very close in temperature to the calorimeter block, a large offset was first observed and the block temperature was somewhat changed. A more reliable effect was observed when the power cell was removed from the sample box. The thermopile output is shown to be $0.4 \mu \mathrm{V}$, the vertical height indicated in figure 2. This corresponds to a self-discharge power of $1.96 \mu \mathrm{W}$ for the battery $(0.4 \mu \mathrm{V} \times 4.90 \mu \mathrm{W} / \mu \mathrm{V}=1.96$ $\mu \mathrm{W})$.

Table 2 lists the self-discharge results found for four power cells. The alkaline cells emit approximately 4 to $5 \mu \mathrm{W}$ of self-discharge and the mercury power cells emit 1.5 to 2 $\mu \mathrm{W}$.

Since only a few measurements were made, these results are not conclusive and perhaps uncertain by \pm 1 or $2 \mu \mathrm{W}$. No attempt was made to obtain typical or representative samples.

The result of additional tests with battery X-3 connected to a $110 \mathrm{k} \Omega$ load in the calorimeter is shown in figure 3 . There were two insertions and removals of the unit from the calorimeter. The second removal in figure 3 was made after the unit had been in the calorimeter for several hours. The bottom portion of table 2 gives the experimental and calculated value of the battery output under a $110 \mathrm{k} \Omega$ load. The calculated power that is dissipated in the $110 \mathrm{k} \Omega$ external resistor is $15.4 \mu \mathrm{W}\left[(1.30 \mathrm{v})^{2} /\left(1.1 \times 10^{5} \Omega\right)\right]$, leaving $2.2 \mu \mathrm{W}$ unaccounted for. This difference may be leakage or self-discharge. However, no great significance can be attached to this difference since only one experiment was performed with one rough measurement being made of the power cell voltage before and after the experiment. The $15.4 \mu \mathrm{W}$ corresponds to the enthalpy of the cell reaction per unit time, when both the battery and resistor were in the calorimeter. This experiment illustrates that power can be measured in the calorimeter with a complete pacemaker and that the measured value for the load plus leakage or self-discharge is near the calculated value for power with the battery under external load.

The results of the measurements with several resistors of different values outside the calorimeter and the power cell inside the calorimeter are shown in figure 4. By measuring the voltage and resistance across the external resistor with a 


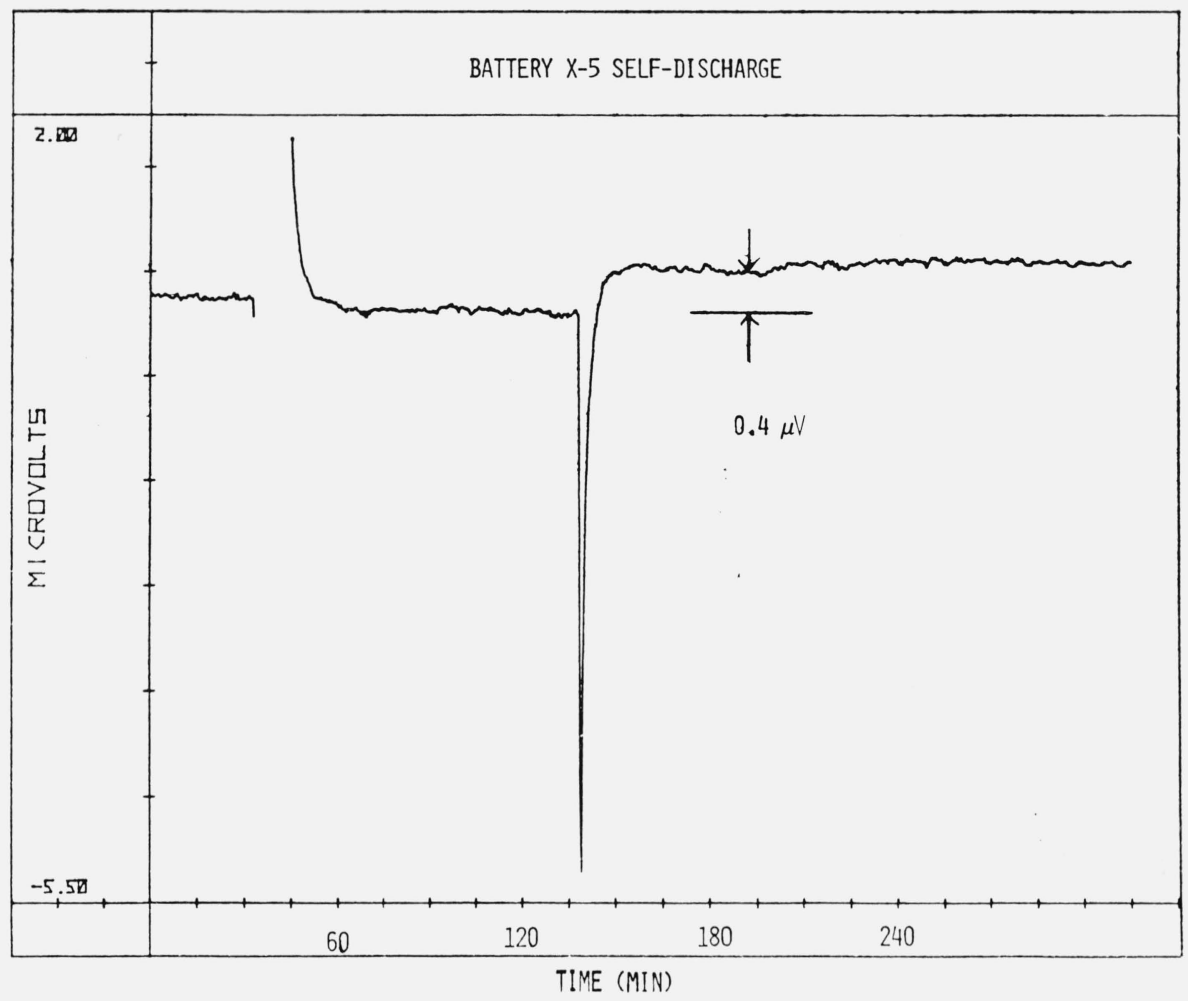

Figure 2. Battery X-5 Self-Discharge

TABLE 2. Microcalorimetric Determination of Self-Discharge

\begin{tabular}{lc}
\hline \hline \multicolumn{1}{c}{ Battery } & Self-Discharge, $\mu \mathrm{W}$ \\
\hline $\mathrm{X}-2 \mathrm{ALK}$ (Camera) & 4.9 \\
$\mathrm{X}-4 \mathrm{ALK}$ (Camera) & 3.9 \\
X-5 Hg(Watch) & 2.0 \\
X-6 Hg(Camera) & 1.5 \\
& \\
Battery Under Load in Microcalorimeter & $\mu \mathrm{W}$ \\
X-3 Hg(Camera) with $110 \mathrm{k} \Omega$ load in calorimeter & 17.6 \\
Calculated value: W $=\mathrm{E}^{2} / \mathrm{R},(1.30)^{2} / 1.1 \times 10^{5} \Omega$ & 15.4 \\
& \multicolumn{2}{c}{ Difference } & 2.2
\end{tabular}

digital voltmeter, the value $W x$, was calculated as the power dissipated in the resistor outside the calorimeter. The external resistors were connected to the battery with copper leads of $0.02019 \mathrm{~cm}$ (No. $32 \mathrm{AWG}$ ) diameter and about 40 $\mathrm{cm}$ in length. Resistors of $5 \mathrm{k} \Omega, 10 \mathrm{k} \Omega$ and $3 \mathrm{k} \Omega$ values were connected and disconnected to battery $\mathrm{X}-2$, as shown in figure 4. Similar experiments were also run on the power cell X-4. Table 3 lists the results of the alkaline power cells $\mathrm{X}-2$ and $\mathrm{X}-4$ under external load conditions. Table 4 lists the results for the mercury battery with external load.
Figure 5 is a plot of the internal power versus the external power, $W i$ versus $W x$, for the three power cells. $W_{i}$ is a linear function of $W x$ and the slope or the ratio $W i / W x$ corresponds to about 4 percent ( $W i$ is 4 percent of $W x$ ) for the alkaline cells and about 1 percent for the mercury cell. The larger $W i$ for the alkaline cell suggests that it has a shorter shelf life than the mercury cell. The points plotted in figure 5 produce lines which extrapolate to near zero $W i$ for zero $W x$ (or open-circuit). Some curvature is evident which is due to the finite internal resistance of the power cell. The method used for measuring $W i$ excluded any open circuit power, because $W i$ was obtained in these external load experiments from the vertical height of the shift in output (for example, A in fig. 4) when the external load was connected and disconnected.

The ratio $W i / W x$ does not indicate any additional lost power above what would be obtained if the cell reaction were ideal. Each type of cell reaction has a characteristic $W i$ which is dissipated. The $W i$ can be calculated from the thermodynamics of the cell reaction if all the thermodynamic quantities are known. The measurements that were made could help to obtain these thermodynamic properties. Theoretically, $W i$ should be a linear function of $W x$ since both are proportional to the number of moles of cell constituents that are reacting. Variation from strict linearity may 


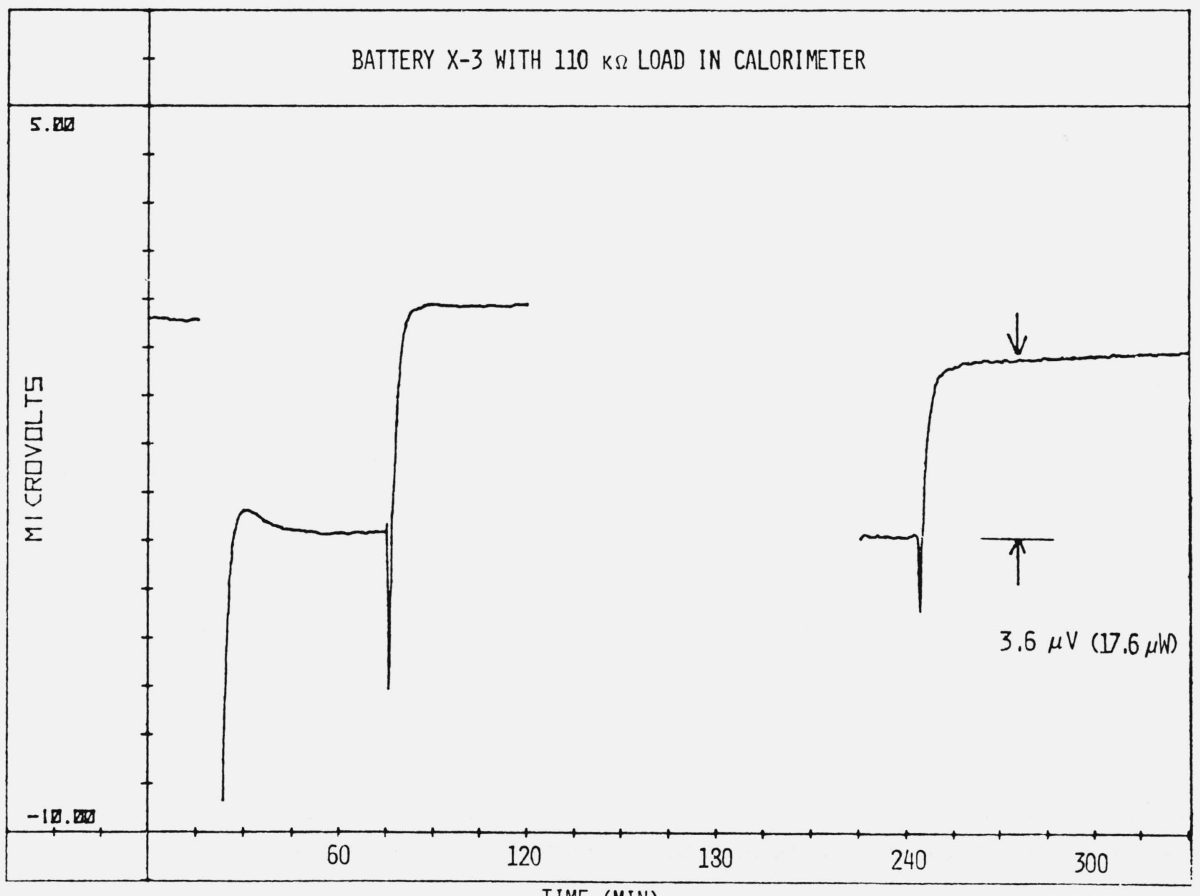

TIME (MIN)

FIGURE 3. Battery $X-3$ with $110 k \Omega$ Load in Calorimeter

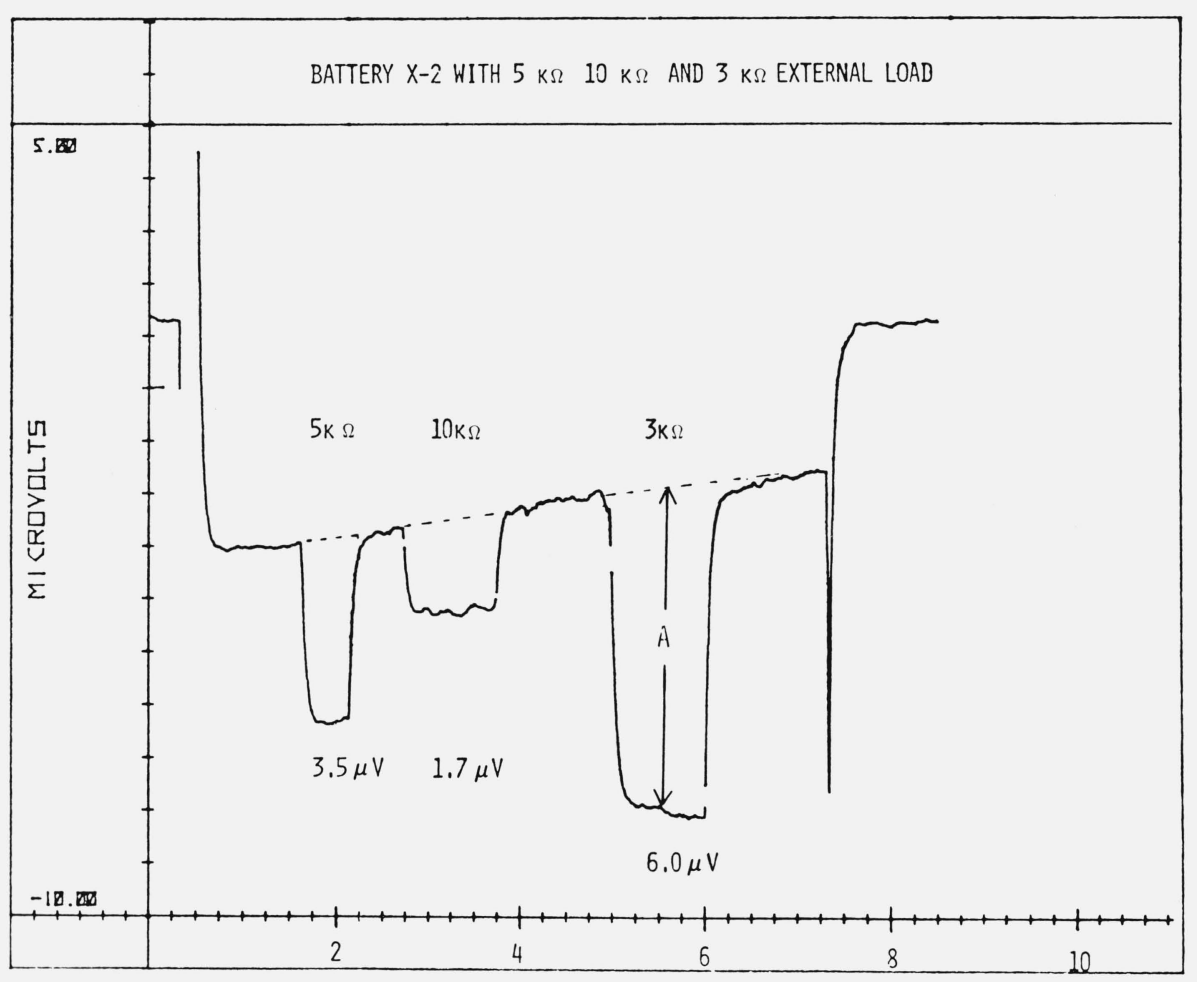

TIME (HOURS)

FIGURE 4. Battery $X-2$ with $5 k \Omega, 10 k \Omega$ and $3 k \Omega$ External Load 
TABLE 3. Alkaline Batteries With External Load

\begin{tabular}{c|c|c|c|c}
\hline \hline \multicolumn{5}{|c}{ X-2 ALK(camera) } \\
\hline$R x /(\Omega)^{\mathrm{a}}$ & $I /(\mu \mathrm{A})^{\mathrm{b}}$ & $W_{i} /(\mu \mathrm{W})^{\mathrm{c}}$ & $W x /(\mu \mathrm{W})^{\mathrm{d}}$ & $W i / W x^{e}$ \\
\hline 10010 & 146 & 8.3 & 213 & 0.0390 \\
4996 & 292 & 17.2 & 426 & 0.0404 \\
3005 & 484 & 29.4 & 703 & 0.04 .18 \\
& \multicolumn{3}{|c|}{$\mathrm{X}-4$ ALK(camera) } \\
\multicolumn{4}{|c|}{} \\
5999 & 144 & 8.8 & 207 & 0.0425 \\
5003 & 285 & 18.1 & 405 & 0.0447 \\
3005 & 476 & 29.9 & 681 & 0.0439 \\
\hline
\end{tabular}

(a) $R x /(\Omega)$, value of the external resistor

(b) $I /(\mu \mathrm{A})$, current through the external resistor

(c) $W i /(\mu \mathrm{W})$, power dissipated internally in battery

(d) $W x /(\mu \mathrm{W})$, power dissipated externally in resistor

(e) $W i / W x$, ratio of internal power to external power

TABLE 4. Mercury Battery with External Load

\begin{tabular}{c|c|c|c|c}
\hline \hline \multicolumn{5}{|c}{$\mathrm{X}-3 \mathrm{Hg}($ camera) } \\
\hline$R x /(\Omega)$ & $I /(\mu \mathrm{A})$ & $W i /(\mu \mathrm{W})$ & $W x /(\mu \mathrm{W})$ & $W i / W x$ \\
\hline 4996 & 269 & 2.1 & 361 & 0.0058 \\
3005 & 445 & 6.6 & 596 & 0.0111 \\
2005 & 666 & 10.8 & 889 & 0.0121 \\
1001 & 1329 & 27.0 & 1767 & 0.0153 \\
\hline
\end{tabular}

(a) For description of column notations, see table 3. be due to the effect of self-discharge, leakage or high internal resistance of the power cell or other non-ideal effects. Such self-discharge or non-ideal effects have not been considered in these calculations.

The data demonstrated that useful measurements of selfdischarge of small power cells could be made with an NBS microcalorimeter [2] or other microcalorimeter of comparable sensitivity. These preliminary results lead to the construction of a larger microcalorimeter that could accomodate the larger pacemaker batteries and pacemaker.

\section{Design and construction of pacemaker microcalorimeter}

This calorimeter is also based on the heat conduction principle [2]. It employs a substitution and guarding principle; that is, dummy vessels can be substituted in the measuring compartment in place of vessels containing active samples. The two additional aluminum blocks act to guard or protect the central measuring compartment from sudden changes in room temperature and serve as sample pre-equilibration chambers. Three solid aluminium blocks, (instead of one), horizontal positioning of the calorimeter, and larger size are features that make this calorimeter different from the NBS Batch Microcalorimeter of figure 1. The three block sections with total dimensions of $28.6 \mathrm{~cm}$ in length by $20.3 \mathrm{~cm}$ in diameter are illustrated in the schematic

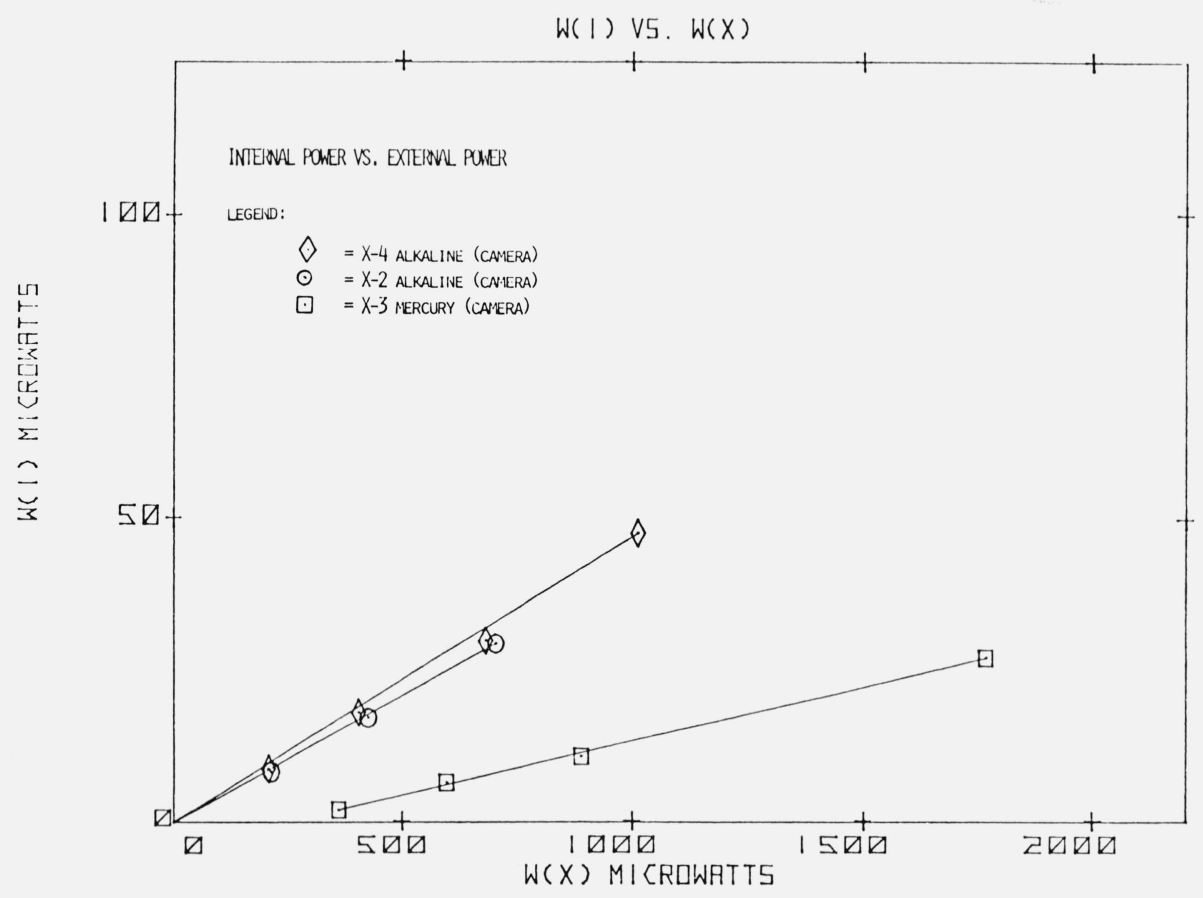

Figure 5. Internal Power vs. External Power 
diagram of figure 6 . The blocks are in good thermal contact with each other and each has a tunnel-like chamber in which reaction vessels are inserted snugly. Each chamber can contain an aluminum reaction vessel of size 7.93 by 6.66 by $2.85 \mathrm{~cm}$. The vessels can contain a battery or a pacemaker or can serve as empty "dummy" vessels.
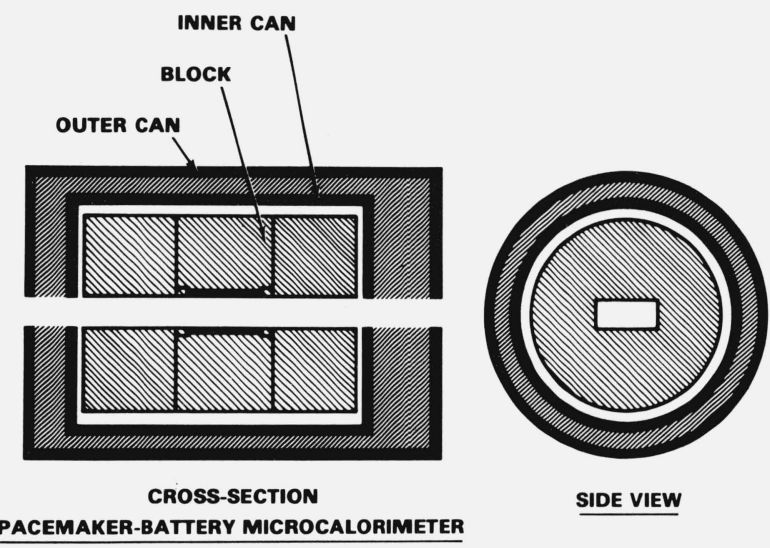

SIDE VIEW
As in the smaller calorimeter, the blocks are surrounded by an inner and an outer aluminum can or shield. The inner can measures $31.8 \mathrm{~cm}$ in length by $24.2 \mathrm{~cm}$ in $0 . D$. and the outer can $43.2 \mathrm{~cm}$ in length by $30.4 \mathrm{~cm}$ in $0 . D$. A heating wire and wires of a Wheatstone bridge were wrapped around the inner can to control the can temperature to \pm $0.001{ }^{\circ} \mathrm{C}$. The temperature of the blocks, which are separated from the inner can by a $1.0 \mathrm{~cm}$ air-space has been found to be constant to about $1 \mu{ }^{\circ} \mathrm{C}$ after an overnight equilibration period. Polyurethane foam fills the $5 \mathrm{~cm}$ space between the inner and outer shield.

A temperature controlled air bath encloses the entire microcalorimeter. For initial experiments on the lithiumiodine power cells, the air bath was maintained at $30 \pm 0.02$ ${ }^{\circ} \mathrm{C}$. The block temperature was held at $32{ }^{\circ} \mathrm{C}$. For measurements on the cardiac pacemaker, the block temperature was controlled at $37^{\circ} \mathrm{C}$. The block temperature can be anywhere between 20 and $40{ }^{\circ} \mathrm{C}$. Under ideal conditions the sensitivity of the instrument is expected to be $0.1 \mu \mathrm{W}$, but it has not yet been attained on active samples.

The microcalorimeter always contains three vessels, one in each block. Initially, the vessel in the heat sensing chamber is empty and the vessels in the two guarding chambers

Figure 6. Cross-Sectional Schematic of Pacemaker Calorimeter

TABLE 5. Alkaline and Mercury Batteries-Self-Discharge

\section{Battery}

16 Mercury, $1.35 \mathrm{v}$ open-circuit

(1.6 cm, diam. x $1.7 \mathrm{~cm}, \mathrm{ht}$ )

16 Mercury, $1.35 \mathrm{v}$ open-circuit (new set) (1.6 cm, diam. x $1.7 \mathrm{~cm}, \mathrm{ht}$ )

8 Alkaline, $1.57 \mathrm{v}$ open-circuit

(1.4 cm, diam. x $4.9 \mathrm{~cm}, \mathrm{ht}$ )

8 Alkaline, $1.57 \mathrm{v}$ open-circuit (new set)

(1.4 cm, diam. x $4.9 \mathrm{~cm}, \mathrm{ht}$ )

\begin{tabular}{|c|c|c|c|c|}
\hline Exp. No. & $\mu \mathrm{V}$ total & $\mu \mathrm{W}$ total & \multicolumn{2}{|c|}{$\mu \mathrm{W} /$ battery } \\
\hline 0615 & 14 & 69 & & 4.3 \\
\hline 0616 & 20 & 98 & & 6.1 \\
\hline 0618 & 24 & 118 & & 7.4 \\
\hline 0620 & 20 & 98 & & 6.1 \\
\hline 0621 & 20 & 98 & & 6.1 \\
\hline 0621 & 22 & 108 & & 6.7 \\
\hline \multirow[t]{3}{*}{0622} & 24 & 120 & & 7.5 \\
\hline & & & $\mathrm{AV}$ & 6.31 \\
\hline & & & SD & 1.07 \\
\hline 0712 & 40 & 196 & & 12.3 \\
\hline 0713 & 32 & 157 & & 9.8 \\
\hline 0713 & 33 & 162 & & 10.1 \\
\hline 0719 & 30 & 147 & & 9.2 \\
\hline \multirow[t]{3}{*}{0725} & 26 & 127 & & 8.0 \\
\hline & & & $\mathrm{AV}$ & 9.88 \\
\hline & & & SD & 1.57 \\
\hline 0623 & 95 & 465.5 & & 58.2 \\
\hline 0624 & 95 & 465.5 & & 58.2 \\
\hline 0627 & 104 & 509.6 & & 63.7 \\
\hline 0628 & 94 & 460.6 & & 57.6 \\
\hline \multirow[t]{3}{*}{0629} & 92 & 450.8 & & 56.4 \\
\hline & & & $\mathrm{AV}$ & 58.82 \\
\hline & & & SD & 2.83 \\
\hline 0630 & 96 & 470.4 & & 58.8 \\
\hline 0705 & 92 & 450.8 & & 56.4 \\
\hline \multirow[t]{3}{*}{0705} & 94 & 460.6 & & 57.6 \\
\hline & & & $\mathrm{AV}$ & 57.60 \\
\hline & & & SD & 1.20 \\
\hline
\end{tabular}


contain power cells or pacemakers. A thin layer of mica lines each vessel to prevent any shorting of power cells to the metal. About $35 \mathrm{ml}$ of hydrocarbon oil is also added to improve thermal contact between the sample and vessel.

Before an experiment, the two vessels containing the test batteries are placed in the guarding chambers and an empty vessel is placed in the heat sensing chamber. About 4 hours are required to reach proper temperature equilibrium. A longer overnight equilibration was found to be better and more convenient. Once equilibrium is attained, the vessels are pushed to new positions in the blocks. For example, the vessel containing the active sample in the first guard chamber is pushed into the heat sensing chamber. In the process, the empty vessel is pushed into the second guard chamber; the second vessel containing an active sample is then placed in the first guard chamber. Differences in signal output are a measure of the power output from the active sample. This arrangement has minimized shifts due to temperature differences in the vessels and resulted in a highly stable baseline.

Commercial alkaline and mercury-zinc batteries were tested for their self-discharge characteristics and the results are listed in table 5 . An example of a plot of 8 alkaline batteries undergoing self-discharge is shown in figure 7 . The $92 \mu \mathrm{V}$ corresponds to $451 \mu \mathrm{W}$ or $56 \mu \mathrm{W}$ self-discharge for each battery. The self-discharge of 16 mercury batteries is shown in figure 8; each battery dissipates about $5.8 \mu \mathrm{W}$.

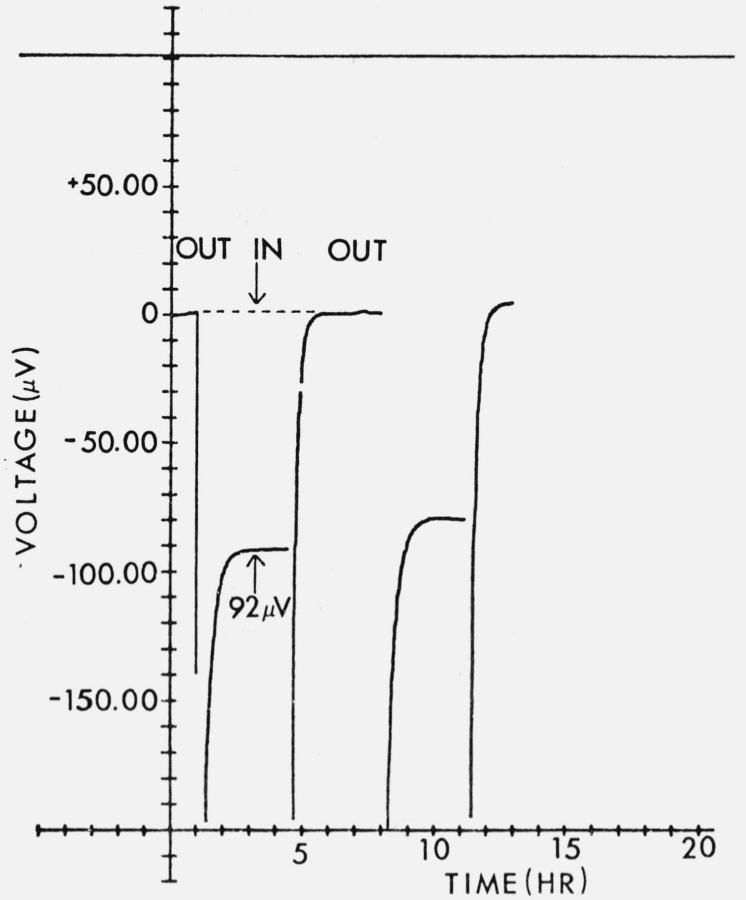

FIGURE 7. Microcalorimetric output voltage versus time for 8 separate open-circuit batteries in and out of the microcalorimeter. A sensor output voltage of $92 \mu \mathrm{V}$ is indicated which corresponds to $451 \mu \mathrm{W}$ or about 56 $\mu \mathrm{W}$ for each battery.

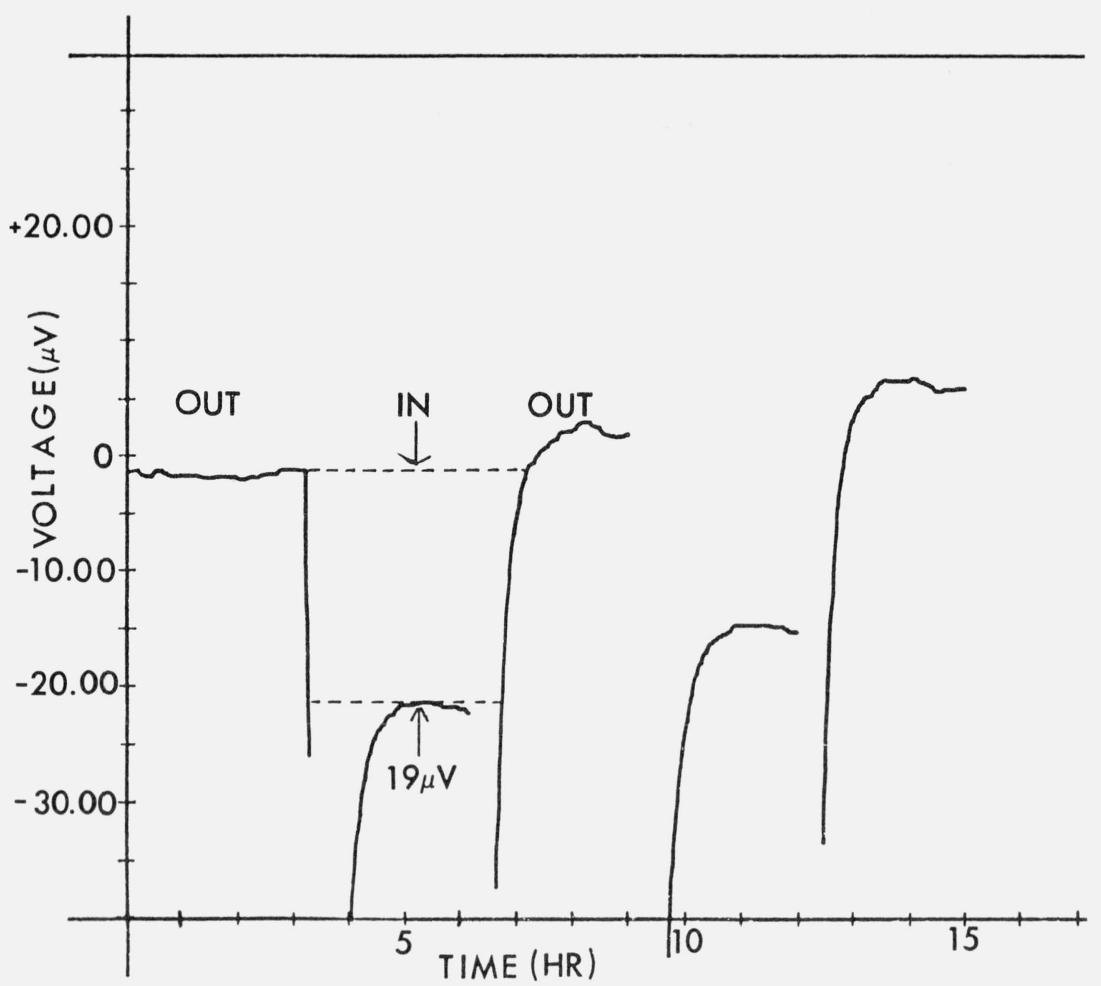

FIGURE 8. Microcalorimetric output voltage versus time for 16 separate open-circuit mercury batteries in and out of the microcalorimeter.

A sensor output voltage of $19 \mu \mathrm{V}$ is indicated which corresponds to $93 \mu \mathrm{W}$ or about $5.8 \mu \mathrm{W}$ for each battery. 
The results confirm that alkaline batteries have a larger self-discharge rate than mercury batteries as shown in table 2.

The results of measurements of open-circuit and load induced power losses in lithium-iodine cells, with three different histories, are listed in table 6 . The batteries are of the same type but were stressed by the manufacturer by connecting a $100 \mathrm{k} \Omega$ resistor for different time periods: 60 days, 10 months and 18.7 months. Figure 9 shows examples of the open-circuit and load induced power loss measurements obtained with lithium-iodine batteries. Figure 9A shows a power loss of $0 \pm 5 \mu \mathrm{W}$ for four lithium-iodine cells under open-circuit conditions. Figure 9B shows $15 \mu \mathrm{V}$ or $73.5 \mu \mathrm{W}$ of power that resulted when one lithium-iodine cell was placed under a $100 \mathrm{k} \Omega$ load in the microcalorimeter. The experimental value of $73.5 \mu \mathrm{W}$ is approximately equal to the value $75.5 \mu \mathrm{W}$ obtained by calculating the power dissipated in the load.

Lithium-iodine batteries from another manufacturer were also measured for their open-circuit self-discharge. One battery was placed in a microcalorimetric sample vessel and then two batteries to determine if twice the amount of self-

TABLE 6. Lithium Iodine Batteries-Self-Discharge and Load Induced Power Loss Battery Dimensions $(1.3 \times 2.2 \times 4.5 \mathrm{~cm})$

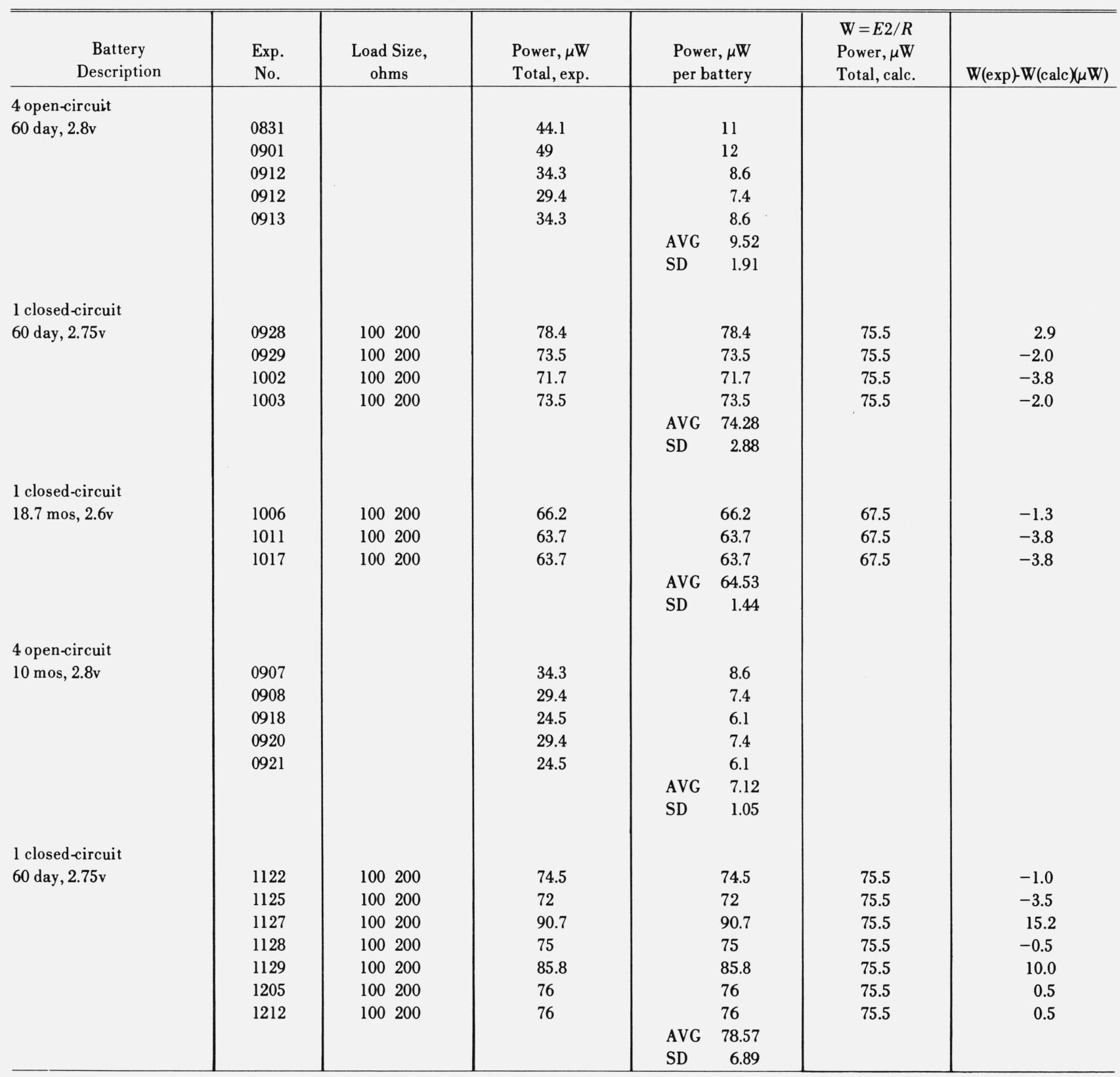




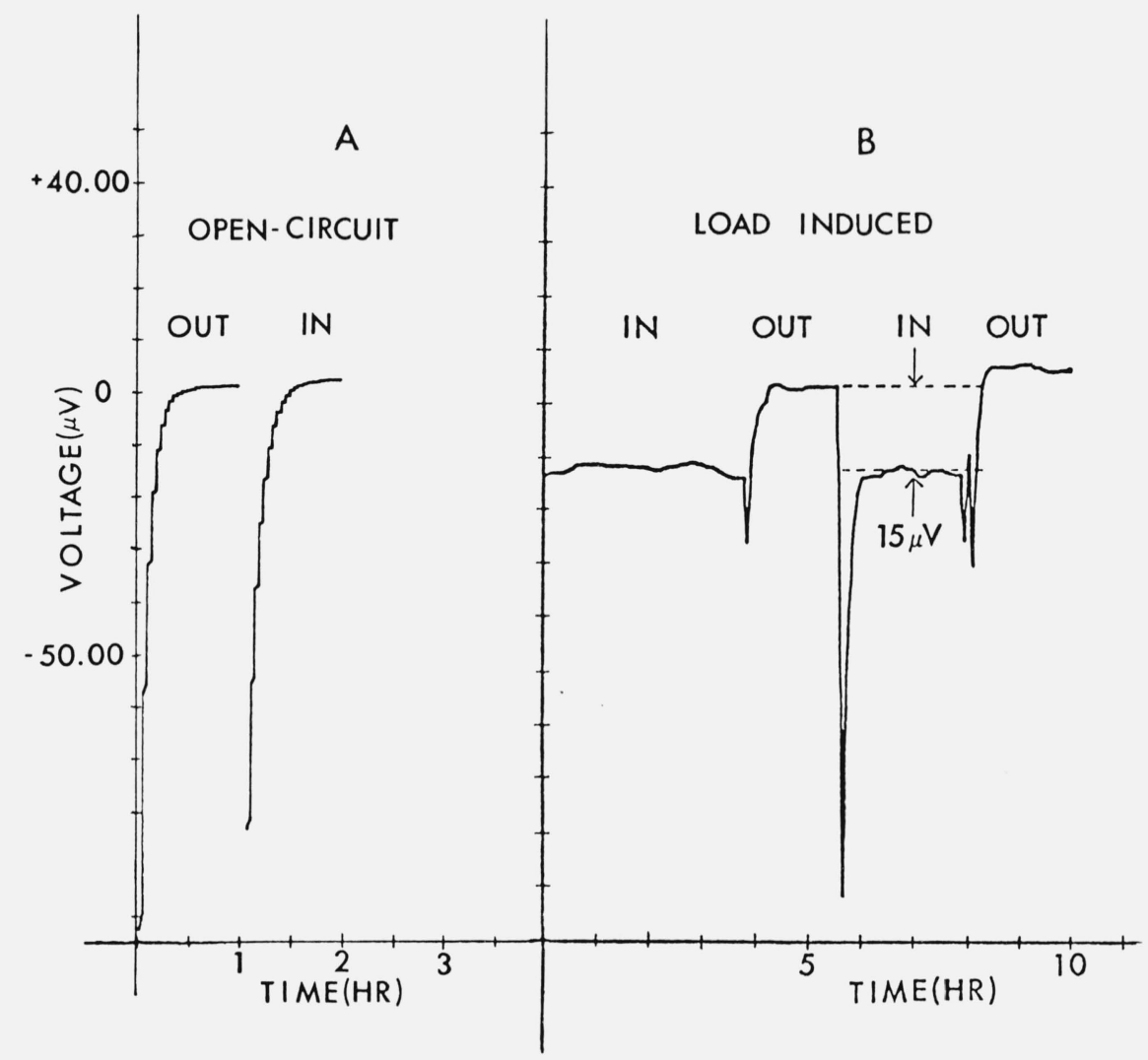

FIGURE 9. A) Microcalorimetric output voltage versus time for 4 Li/I batteries (open-circuit and previously discharged for 60 days through $100 \mathrm{k} \Omega$ ).

A sensor output voltage of $\pm 1 \mu \mathrm{V}$ is indicated which corresponds to $\pm 5 \mu \mathrm{W}$ or $\pm 1 \mu \mathrm{W}$ for each battery.

B) Microcalorimetric output voltage versus time for $1 \mathrm{Li} / \mathrm{I}$ battery (under load of $100 \mathrm{k} \Omega$ in the microcalorimeter.)

A sensor output voltage of $15 \mu \mathrm{V}$ is indicated which corresponds to $73.5 \mu \mathrm{W}$ of power.

discharge could be detected by the microcalorimeter. The results in table 7 show that about twice the power was indeed dissipated as self-discharge when two batteries were measured as compared to the power loss in one power cell.

TABLE 7. Lithium Iodine Batteries

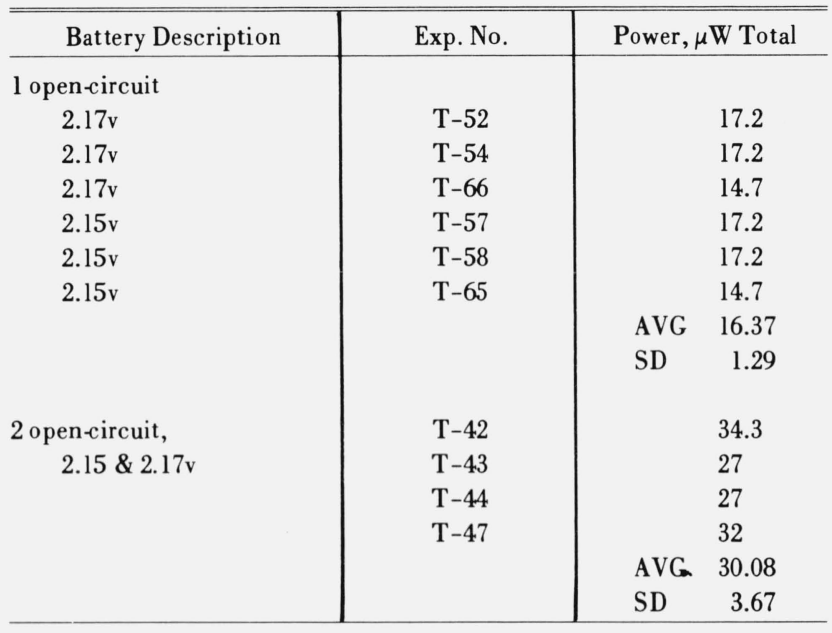

We also measured the heat loss from two different pulsing pacemakers; the heat loss rates for each pacemaker are listed in table 8. Pacemaker \#l contained two Li/I batteries and was losing an average of $45.7 \mu \mathrm{W}$ of power. Pacemaker $\# 2$ contained one Li/I battery and was losing an average of 28.4 $\mu \mathrm{W}$.

TABLE 8. Self Discharge of Pacemakers

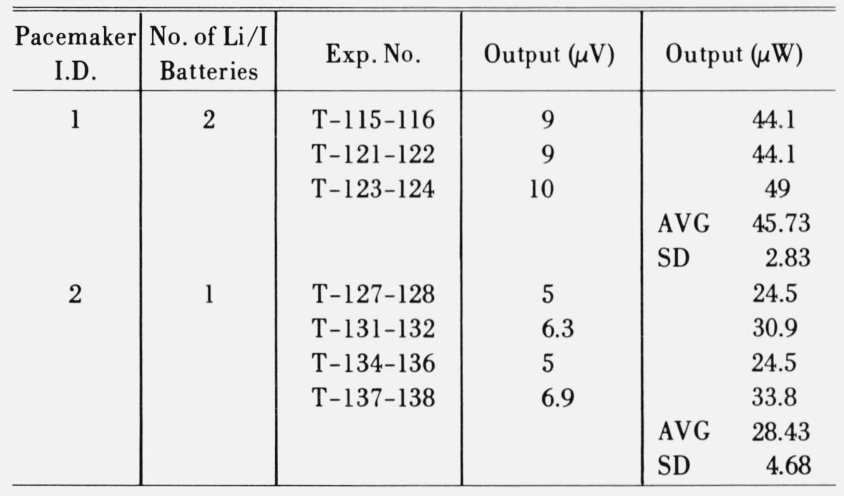




\section{Summary}

We try to explain the quantities being measured per unit of time by using the following thermodynamic equation,

$$
-\Delta G=-\Delta H+T \Delta S
$$

where $\Delta G, \Delta H$, and $\Delta S$ are the changes of the Gibbs energy, enthalpy, and entropy, respectively, and $T$ is the absolute temperature. A negative sign denotes an exothermic reaction, $-\Delta H$, or that heat is being given off by a battery to the calorimeter and $-\Delta G$ denotes the process tends to proceed spontaneously [3]. It is assumed that the reaction takes place at constant temperature and pressure. Each of the quantities in the equation has been measured in the present experiments; see figure 10 .

a)

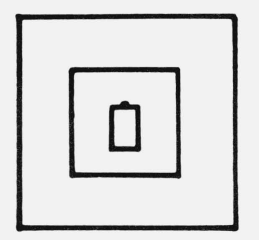

SELF-DISCHARGE

b)

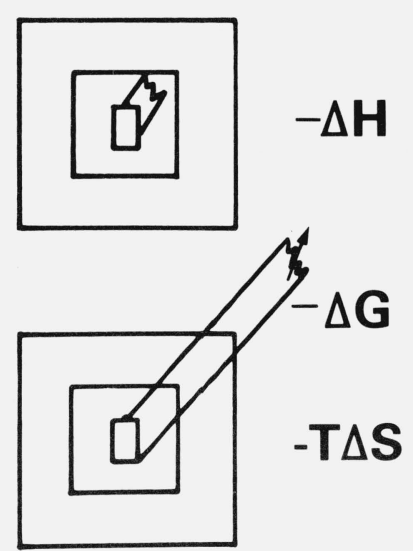

FIGURE 10. Illustration of Thermodynamic Quantities measured.

(a) Battery in calorimeter with no load; self-discharge is measured by calorimeter.

b) Battery with load inside calorimeter; $-\Delta \mathrm{H}$ measured by calorimeter.

c) Battery in calorimeter, load outside calorimeter; $-\mathrm{T} \Delta \mathrm{S}$ is measured by calorimeter, $-\Delta \mathrm{G}$ is dissipated in the load outside the calorimeter.

When an open-circuited power cell is placed alone in the calorimeter, then the self-discharge power is measured by the calorimeter. Side reactions, such as corrosion of the metal components, may account for some of this self-heating.
When the power cell has a resistor placed across it and both the power cell and resistor are placed in the calorimeter, then the cell reaction corresponding to $q=-\Delta H$ is measured by the calorimeter. Self-discharge may also be occurring. When a power cell and resistor are connected with the resistor placed outside the calorimeter, then the heat corresponding to $q=T \Delta S$ is measured by the calorimeter. The useable energy, $-\Delta G$, is determined electrically by measuring the current and voltage across the external resistor. In each of these cases the measured quantity is power rather than energy.

Tests of internal power $W_{i}$ as a function of external power $W x$ yielded results which are characteristic of the ideal cell reaction; that is, $W i$ is a linear function of $W x$ (within the precision of the measurements). This was found for both the alkaline and mercury cells.

For the kinds of cell reactions that take place in alkaline and mercury batteries, the $T \Delta S$ can be a large fraction of $\Delta H$ as in the silver-zinc battery. The literature value of the $T \Delta S$ quantity for the reaction $\mathrm{Ag}_{2} \mathrm{O}$ (c) $+\mathrm{Zn}(\mathrm{c})+\mathrm{H}_{2} \mathrm{O}$ (liq) $\rightleftharpoons 2 \mathrm{Ag}(\mathrm{c})+\mathrm{Zn}(\mathrm{OH})_{2}(\mathrm{c}, \beta)[4]$, where (c) signifies condensed phase, is $-19.859 \mathrm{~kJ} / \mathrm{mol}$ [5] and $\Delta H$ is $-325.034 \mathrm{~kJ} / \mathrm{mol}$ [5]. The $T \Delta S$ is 6.11 percent of $\Delta H$. On the other hand, the literature value of the $T \Delta S$ quantity for the reaction $\mathrm{Li}(\mathrm{c})+1 / 2$ $\mathrm{I}_{2}(\mathrm{c}) \rightleftharpoons \mathrm{LiI}(\mathrm{c})$ is very small, $-0.22 \mathrm{~kJ} / \mathrm{mol}$ compared to $\Delta H$ of $-273.6 \mathrm{~kJ} / \mathrm{mol}$ or only 0.08 percent of $\Delta H$ [6]. The small value for $T \Delta S$ is corroborated by our experimental data (see table 6 and fig. 9).

The pacemaker microcalorimeter is capable of nondestructively measuring small heat losses on the order of microwatts from a power cell or pacemaker. This instrument has already found many applications in the battery manufacturing industry as a repair check on faulty batteries in which measurements are made before and after repair to determine if the repairs made were correct. It can be used for testing the heat output of new batteries and pacemakers in a quality control test, for development of new power sources, and for determining the shelf-life of batteries. Greatbatch, et al [7], have reported detection of heat losses of $10-50 \mu \mathrm{W}$ in new pacemaker batteries which was traceable to the continuous curing of plastic materials in the battery. True internal shorts have produced $1000-2000 \mu \mathrm{W}$ of heat. They report also that the microcalorimeter should prove invaluable for early nondestructive identification of parasitic power losses in batteries and pacemakers.

The pacemaker microcalorimeter, with minor design modifications, is expected to have commercial and research applications beyond the study of self-discharge of power sources and pacemakers, such as, detection of bacterial contamination in dried food materials and the study of radiation effects on the metabolism of living cells as being undertaken by the Bureau of Radiological Health, Department of Health and Welfare. 


\section{References}

[1] Prosen, Edward J., Design and construction of the NBS Clinical Microcalorimeter, NBS Report 73-179 (April 1973).

[2] Prosen, Edward J. and Colbert, Jennifer C., Microalorimetric study of cardiac pacemakers and batteries, National Bureau of Standards NBSIR 77-1310 (September 1977).

[3] Wood, Reuben E., Introduction to Chemical Themodynamics, Appleton-Century-Crofts, New York, (1970).
[4] Falk, Uno S. and Salkind, Alvin J., Alkaline Storage Batteries, John Wiley and Sons, Inc., N.Y. p. 435, (1969).

[5] Wagman, D. D., Evans, W. H., Parker, V. B., Halow, I., Bailey, S. M., and Schumm, R. H., Nat. Bur. Strand. (U.S.), Tech. Note 270-3, 268 pages (January 1969); and Tech. Note 270-4, 152 pages (May 1969).

[6] Values for the formation of Lithium were provided by Richard Schumm, NBS Chemical thermodynamics Data Center.

[7] Greatbatch, W., McLean, R., Holmes, W., Holmes, C., A Microcalorimeter for Nondestructive Analysis of Pacemakers and Pacemaker Batteries, IEEE Trans. on Biomedical Engineering, BME-26(5), 306-309 (May, 1979). 
